\title{
The Perceived Purpose of Professional Development Programs from the Science Teachers' Perspective in Saudi Arabia
}

\author{
Mobarak M Alqahtani ${ }^{1}$ \\ ${ }^{1}$ Candidate Faculty of Education- Monash University, Australia \\ Correspondenece: Mobarak M Alqahtani, candidate Faculty of Education- Monash University, Australia
}

Received: December 19, 2019

Accepted: February 11, $2020 \quad$ Online Published: February 19, 2020

doi:10.5539/mas.v14n3p18

URL: https://doi.org/10.5539/mas.v14n3p18

\begin{abstract}
The Saudi Arabian Government has made a substantial investment in reforming the science curriculum in Saudi Arabia. Creating sustainable education is a top priority of Saudi Arabian policy makers (BenDehash, 2005). The level of education received by students must prepare them for fieldwork in their area of expertise and, ultimately, help them to contribute to improving the economic position of the country. Studies have shown that reforms to the science curriculum that consider developments in local contexts increase the quality of students' outcomes. For this reason, the government has developed a new curriculum in 2008 to target key learning areas of students and, ultimately, increase their academic performance. As BenDehash (2005) rightly asserts, radical development of the old curriculum addressed the rapid changes in local and international environments and assisted Saudi students to gain appropriate and relevant skills that will allow them to contribute both locally and internationally. This study will seek to address the discrepancies in PD programs in Saudi Arabia as well as provide insight for other countries in implementing successful PD programs for teachers.
\end{abstract}

Keywords: curriculum, professional development programs, science teachers, global education, teacher

\section{Aim of this Research}

This research explores Saudi Arabian science teachers' perceptions of PD programs. The research is concerned with determining the perceived purpose that science teachers understood from attending PD programs. In order to achieve this objective, the research aims to address the following research question: What is the perceived purpose of mandatory PD programs from science teachers' perspectives?

\section{Introduction}

Despite the introduction of the reformed science curriculum, students' results are less than what was expected. The recent International Mathematics and Science study revealed that Saudi students are below the world average in applying knowledge and understanding problem solving. This may indicate weaknesses within science teaching methods and, furthermore, the level of appropriate PD received by teachers of science in Saudi Arabia (Alabdulkareem, 2017) that allows them to adapt to this new curriculum.

The implementation of the new curriculum has been a challenge for teachers, as they are accustomed to traditional methods and the new curriculum requires them to develop new skills, knowledge and ways of teaching. Positive adaptation to this new curriculum includes development of skills in problem solving, critical thinking and collaborative learning, as well as being able to access and respond to modern sources of knowledge (BenDehash, 2005). Therefore, adaptation to the new science curriculum requires a change in teacher practices and, moreover, "the curriculum and instruction changes need to be reflected in the professional learning of current and future science teachers" (Hamdan, 2015, p. 12).

Currently, evidence shows that in spite of attending PD programs, teachers in Saudi Arabia continue to rely heavily on traditional teaching methods and do not spend enough time interacting with their students or use new technology in the classroom (Al-Qahtani, Awadh, \& Higgins, 2013). This study will seek to address the perceived purpose of PD programs in Saudi classrooms, however the findings may also offer some guidance and support for educational institutions universally to enhance their own PD programs which address the needs of science teachers. 


\section{Purpose of Professional Development for Teachers}

The need for effective professional development programs is especially crucial in the context of recent curriculum reform in Saudi Arabia. The country has adopted new science curricula following the guidelines of renowned global publishers like McGraw-Hill. However, the introduction of the new science curriculum is posing challenges for science teachers, as it requires a paradigm shift from a teacher-centred to a learner-centred pedagogy (Mansour, Heba, Alshamrani, \& Aldahmash, 2014).

In a practical sense, the goal of PD programs is to modulate the behaviour and practices of teachers in the classroom environment. Hence, the best measure of a PD program's efficacy is its translation to changes in student and teacher outcomes (Fishman, Marx, Best, \& Tal, 2003).

In designing their model of effective learning in PD programs, Fishman et al. (2003) followed the work of Richardson (1996), who proposed that the primary objective of PD programs "should be to foster changes in teachers' knowledge, beliefs, and attitudes, because these components of teacher cognition show a strong correlation to teachers' classroom practices" (p. 645). However, measuring the changes in teachers' beliefs and attitudes is difficult and must be done over the long term. Many of the current measures involve "end-of-workshop evaluations ... [which] are measures of teacher belief, not knowledge" (Fishman et al., 2003, p. 645). Teacher feedback may help to assess the effectiveness of a PD program as well as identify if they are aware of its purpose.

PD programs place a strong emphasis on improving teacher practices; they allow for teachers to understand their role, develop a sense of occupational identity and achieve clarity in terms of their practices. A study conducted by Mackay (2017) identified that PD programs have three main purposes within a professional environment: knowledge competence, social networking opportunities and enhanced self-worth value of teachers. Knowledge competence concerns enhancing the professional skills of teachers through upgrading their knowledge and skills in the classroom environment. Secondly, PD programs can provide teachers with the opportunity to network with colleagues in their field. These social networks facilitate a teacher's sense of belonging and develop their reputation as a respected professional. Lastly, the PD program aims to increase teachers' self-worth and provide teachers with the opportunity to reflect on their strengths, successes and professional achievements (Mackay, 2017). Therefore, teacher awareness of the PD's purpose and benefits as outlined by Mackay (2017), holds significant potential to enhance the benefit teachers derive from professional development, on both a professional and personal level.

\section{Saudi Context}

In Saudi, there is a gap between the teaching skills taught in PD programs and what the government plans to implement. Thus far, the objectives of the PD program have not been realised in science classrooms around the nation. According to Almazroa and Al-Shamrani (2015), this gap is due to, among others, a deficiency of "guiding goals" (p. 11) for the PD programs of science teachers among educational districts. It is important that PD programs have clear goals in order to help science teachers improve their practices. The PD should clearly stipulate the goals of the PD program for the participants in order to inform them of what they are going to learn and increase their awareness of the PD's intentions. In doing so, the PD can have a better influence on leading teachers to practise new teaching methods and make teachers more aware of what the government aims to achieve with the PD.

\section{Importance of Improving Teaching Practice}

Improving teaching practices is considered an important factor in improving overall student learning outcomes. Therefore, it is crucial to determine how to improve teaching practices among teachers. The first step in this improvement process is determining whether professional development or professional learning initiatives bring about improved teaching practices.

McGinnis et al. (2012) argue that there have been many efforts to improve science teaching around the world with comprehensive teacher preparation and quality professional development, as science teachers have vital roles in enhancing science literacy.

Science teachers need to keep up to date with ongoing changes in science-related knowledge that are taking place outside the classroom, such as recent advancements in information and communication technology or contemporary scientific developments. Rennie (2011) argues that busy teachers need to expand their content knowledge and there must be ways which "enable them to bring contemporary science into the classroom" (p. 22). Teachers' in-service professional development is extremely important for addressing this need as it is the quickest way for them to enhance their knowledge in the field and understand any new requirements for teaching 
(Dastgeer, Tanveer, Atta, \& Ahmad, 2017). According to Dastgeer et al. (2017), professional development plays a critical role in developing in-service teachers' level of confidence and attitudes, which have positive effects on students' outcomes.

The need for a professional learning program in Saudi Arabia (SA) is especially crucial following the recent reforms in the science curriculum that call for changes in teaching approaches. Saudi science teachers are struggling to implement the guidelines of the new science curriculum, as there are not enough quality professional development programs that precisely address the growing needs of the teachers (Mansour et al., 2014). While problems of limited teaching resources and aids are mentioned by teachers as creating challenges for teaching, one of the most frequent complaints of the Saudi science teachers is lack of proper professional support (Sywelem \& Witte, 2013). Therefore, in order to ensure more positive outcomes in the education arena, it is of the utmost importance to invest more in teachers' development initiatives rather than focus on other physical resources (Sywelem \& Witte, 2013).

It is also argued that in order to ensure ongoing professional development, teachers need to be engaged in a professional learning community of science teachers with common interests (Panizzon, 2011). However, this kind of community usually exists in urban areas, and teachers in rural and remote areas have little access to such professional networks (Panizzon, 2011). Moreover, the majority of the science teachers in rural areas are likely to be either fresh graduates or in the beginning phase of their teaching careers. According to Monk (2007), "rural school districts make do with less qualified pool of candidate and are more likely to face retention problems" (p. 162). Hence, it is very challenging for these new and early career teachers to enhance their pedagogical learning if they are not in touch with more experienced teachers (Panizzon, 2011). The challenges of lack of community engagement and scarcity of teaching resources are even more acute in the southern region of Saudi Arabia, which is the area studied in this research. There are no higher education institutes like universities or resource centres (e.g. libraries or museums) in this region, which makes it difficult for teachers to access professional and teaching development resources.

\section{Methodology}

This study used a qualitative approach to data collection techniques. The first phase of the data collection involved observing three PD programs for science teachers. Empirical in nature, the observations aimed to record the events that unfolded during the PD and the actions of the participants involved in the PD pro study recorded behaviours relevant to answering the main research questions in order to improve understanding of the context and nature of the mandatory PD programs. The second tool of data collection used in this study was an open-ended questionnaire which was employed to develop insight into the situation and help choose potential interview participants. The third research tool used in this study was the semi-structured interview as it afforded an opportunity to explore participants' views on aspects of the research question and offers a deeper understanding of the perceptions of science teachers about the effectiveness of professional development.

\subsection{Sampling}

An open-ended questionnaire was completed by 81 science teachers who attended the in-service PD program in the Sarat Ubaidah region. Science teachers were recruited via letters sent by the Saudi Department of Education to all primary, middle and secondary school principals.

Of the 414 science teachers listed in that region, a total of 81 teachers, comprising both experienced and new teachers, attended the five mandated PD programs and completed a questionnaire. Observations were conducted only on the three PD programs detailed above (attended by 47 teachers).

Of the total 74 questionnaire respondents, 38 science teachers consented to participate in the interview; of these, only 21 participants engaged in the interview phase. The remaining 17 participants refused to engage in the interview either because they no longer wished to participate in the study, did not wish to be recorded, or failed to answer attempts at communication.

\subsection{Data Analysis}

The data collected from this study, required guidelines to ensure the data was analysed in a systematic way. The notes recorded during the observations were reviewed multiple times to identify common issues before categorising them into broad themes. The data collected was based on the researcher's observations of the level of engagement exhibited by the participants, as well as the questions they asked the presenters during the PD seminars. The notes recorded during the observations were reviewed multiple times to identify common issues before categorising them into broad themes. 


\subsubsection{Open-Ended Questionnaire}

The following steps were followed to analyse the questionnaire data; commonalities between responses were read and grouped together, similar responses were colour coded into the same category, translated from Arabic to English (to ensure categorisation and coding occur before any potential changes in meaning could occur), and labels were used as themes to list and present findings for a certain question.

\subsubsection{Interview Analysis}

The data generated from the interviews were transcribed from the audio recordings. The participants' gestures, volume, emphasis, vocal intonation and body language were noted during the interviews.

\subsubsection{Coding to Build Description and Broad Themes}

The coding process involved repeated readings of the interview transcripts to identify some broad headings for categorising the various types of responses. Original plans to use computer software like NVivo were abandoned after realising the program did not support language scripts written from right to left (such as Arabic). Instead, different colours were used to highlight participant responses and codes generated manually in Microsoft Word. Upon completing the coding in Arabic, similar codes were compiled to generate broad themes from the interview.

\subsubsection{Represent and Report Qualitative Findings}

The findings were presented in the form of narrative discussions. The narrative texts included quotes from selected interviews (translated into English) that captured the typical feelings and experiences of the participants. A certified Arabic/English translator double-checked the participants' quotes to ensure the accuracy of the translations. The data was interpreted by comparing the findings from interviews against the research question and relevant literature as well as the personal experiences and contextual knowledge of the researcher. Finally, triangulation of data was used to promote the validity of the research.

\section{Results}

\subsection{Observation Findings}

This section presents the observation findings from the three PD program sessions: 'New Strategies in Teaching Science', 'Excellence in Teaching Science' and 'Active Learning'. The results are presented under the headings of purpose, value, benefits, barriers and needs.

\subsection{Questionnaire Results}

\subsubsection{Purpoe}

Participants were asked to state the purpose of the PD programs that they had been attending currently as well as previously, and their responses are illustrated in Figure 1. These responses were related to six types of purpose: teacher action, knowledge, teaching strategies, students, skills and education in general. 


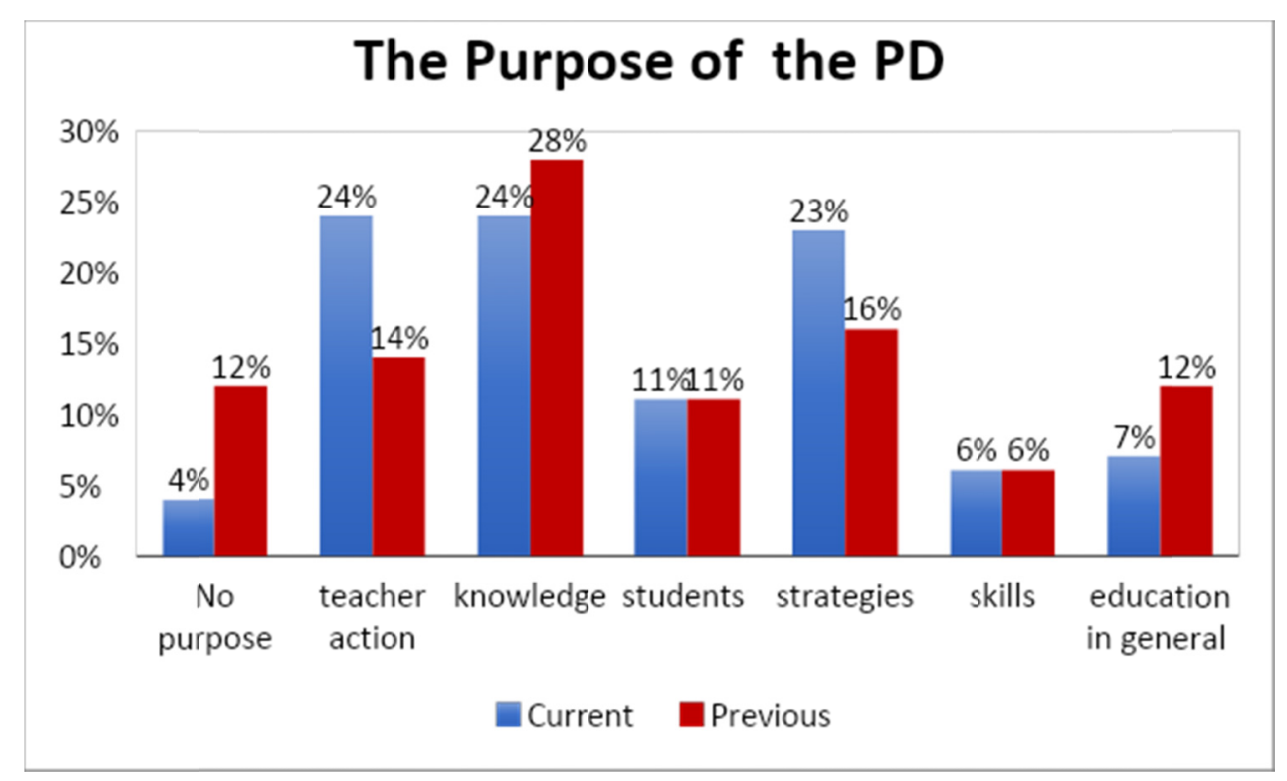

Figure 1. Participants' beliefs of the purpose of professional development programs (open-ended questionnaire)

\section{Knowledge}

Almost a quarter (24\%) of the PD participants expressed that the purpose of the current PD was related to the knowledge they had gained, while $28 \%$ of the participants reported that the purpose of the previous PDs was related to the knowledge. These participants found that the current PD provided them with useful knowledge. For example, participants said the purpose of the PD program was "developing professional knowledge". Some participants stated that the PD provided them with relevant knowledge as "the goal [of PD] is to spread cultural awareness" and the programs "update [teachers] with the latest teaching methods in the education field".

While explaining the purpose of the previous PD, participants also alluded to how the PD allowed for teachers to "cope with the curriculum" and provide a "comprehensive view of professional development". The varied responses of the teachers suggest that educators derive various benefits from the $\mathrm{PD}$, and their responses relate to their experience with the PD.

\subsection{Teaching Strategies}

The results showed that $23 \%$ of the current PD participants mentioned the purpose of the PD being related to teaching strategies, and $16 \%$ reported the same about the previous PD. The participants found that the purpose of the current PD was to discuss teaching strategies for teaching science lessons. For example, one participant said the purpose of this PD was to "explain some education strategies". Another participant stated that the purpose of this PD was to "provide the teacher with new methods used in the teaching field". One participant added that this PD's purpose was to "illustrate teaching methods besides using the useful strategies". Other participants described the purpose of the current PD as a way of changing the teaching methods that stressed "moving from the traditional teaching to the modern teaching such as the active learning". For the previous PD programs, the participants indicated that the purpose of the PD was to provide the teacher with new teaching methods. For example, one participant said the purpose of the previous PD programs was to "develop the teaching strategies and methods and provide the teacher with new teaching strategies". In addition, another participant mentioned that the purpose of previous PD was to "introduce him [teacher] to the new strategies and how to apply them correctly".

\subsection{Teacher Action}

It can be seen in Figure 1 that $24 \%$ of teachers referred to the purpose of the current PD programs as relating to teacher action, while $14 \%$ stated a similar purpose for the previous PD programs. With regard to the current PD, one participant stated that the current PD enabled "exchanging of experience for the participants". Furthermore, it was reported that the PD focused on "raising the performance level and qualifications of the teacher", and "gaining experience and exchanging it in the education field". Some other participants highlighted that the current PD promoted "development of the teaching tools by using experience and sharing ideas", thereby "improving the teacher's productivity" and "developing the teacher's performance in the academic discipline". Moreover, some 
participants claimed that the current PD program encouraged "sharing of experiences between the teachers", and another participant stated that it "raised the teacher's performance level" and enabled them to "exchange their experience" amongst themselves.

Again, when the participants came to describe the purpose of the previous PD program, one claimed that it (PD) allowed for "discussion with colleagues and the exchange of experience", whereas another participant said it enabled them to "take their experience and apply it to the education field". As one participant stated, the purpose of the previous PD was to provide a chance to "increase experience and apply it", while another described it as "raising the teacher's efficiency level and providing various experiences for the teacher". Additionally, one more participant claimed that the previous PD's purpose aimed to "give him [the teacher] experience from the supervisors and the colleagues", and yet another participant highlighted that it "aimed at developing the performance at the workplace".

\subsection{Students}

According to participants, $11 \%$ stated that the purpose of both the previous and current PD program was to focus on the students. In relation to the current PD program, one participant explained that it promoted "raising the academic level of the student", while another stated it promoted the importance of "making the student inquisitive and get the information by himself". Other participants claimed that the current PD aims to highlight the "ease of access of the information for the students with flexibility", and the importance of "presenting the academic subject to the students easily and clearly" while "giving the student more space to explore". With regard to the previous PD session's purpose, one participant indicated that it was focused on "raising the education level of the students, while, on the other hand, enabling them [teachers] to cope with the changes [in teaching method] that could help them to be unique in their education". Moreover, other participants stated that the purpose of the previous PD programs was to highlight the importance of "preparing a student who can get the information by himself", while another said it emphasised "simplifying and facilitating students" access to the information" in order to produce "students graduating with high intellectual qualifications".

\subsection{Improving Education in General}

The results showed that $7 \%$ of participants described the purpose of the current PD program to be improving education in general, while $12 \%$ of participants shared the same opinion for the previous PD. One participant said that the current PD discussed "education career with all its aspects [including management and teaching methods]". Another participant stated the current PD program's purpose was to "raise the level of all educational aspects to reach the desired goal".

With regard to the previous PD session, a participant quoted its purpose as "presenting education in a good way", while another described it as "changing the reality of current education for the better".

\subsection{Skills}

Only $6 \%$ of the participants mentioned that the purpose of the current and previous PD programs was linked to the skills of science teachers. One participant mentioned that the purpose of the current PD was to emphasise that "professional development programs are so significant for the teachers to develop their skills". Furthermore, another stated the purpose was to "develop the teacher's skills and abilities and introduce him to creative ways in teaching the subject". In relation to the previous PD program, a participant stated its purpose was to promote "the development of the teacher's skills to cope with the new science curriculum", while another suggested it was focused on "changing and acquiring some skills".

\subsection{No Purpose}

The responses showed that $4 \%$ of participants did not specify a purpose attributed to the current PD program, while $12 \%$ of participants also did not specify or identify a specific purpose for the previous PD. With regard to the current PD program, one participant gave the response of "good", while another mentioned that "these programs didn't give us the main goals". Additionally, another regarded it as "average and regular with no new information". With regard to the previous PD, one participant commented that it was "good in general", and another stated that it was "good, it's useful but not everyone makes use of it". Furthermore, one participant described it as "good somehow", and another mentioned that he was participating in the PD "only to record the attendance to do the duty". 


\section{Interview Results}

\subsection{Purpose of Professional Development Program}

The interview analysis revealed that participants mentioned the purpose of the PD they have attended. These purposes, as mentioned by participants, can be categorised under four types: those that are related to teaching strategies, students, general instruction and education in general. However, a number of participants were unable to mention any purpose of the PD because it is an issue about which they were uncertain.

\subsection{Specific Purposes of Professional Development}

Some participants mentioned the purpose of PD in specific terms. They mentioned particular areas of their teaching that have been addressed by the PD. However, it was reported by participants that sometimes there was a mismatch between the stated topic and the actual focus of the PD. This problem was observed by one participant who said, "I attended a professional development program with the topic active learning, but it was actually more relevant to the way of dealing with students than anything else" (Muadi).

In addition, it was stated that the purpose of some PD was to provide science teachers with some instructions, and this was reflected in the views of one teacher who said that "some of the professional development programs were a meeting only; meetings between the supervisor and teachers and only he said do this and that, it was just instruction" (Saleh).

\subsection{No Idea about Purpose of Professional Development PD}

There were some participants who admitted that they did not know the purpose of the PD. They thought the goals of PD were not made clear to them and they received no or little information about the PD prior to attending. Participants also mentioned that most of the PDs programs were unclear about the purpose and they try to cover many issues. One teacher reported that "most of professional development programs had no clear purpose... [there was] something about education issues, teaching strategies and classroom management ...we got lost at the end of the program" (Rubaie)

\subsection{Discussion and Recommendations}

The following sections will discuss the answers to this study's research question from the perspective of science teachers.

In an attempt to present the implications of the findings of this work, the Australian Institute for Teaching and School Leadership's (AITSL) (2015) model of behaviour change is used (Figure 2). This model was chosen because of its alignment with the aims of the Saudi Government and their professional development efforts. The government of Saudi Arabia notes the need to move science teachers into a new way of thinking about learning and teaching that focuses on active, student-centred learning, which requires new attitudes to pedagogy. The AITSL model allows for an exploration of the process in more detail.

\subsection{AITSL Standard Change Process}

Change is unlikely unless teachers recognise the benefits of undertaking new processes. Therefore, it is beholden on the designers and facilitators of the PD programs to address teachers' attitudes to change from the outset of the sessions. According to AITSL (2015), persuading educators to change involves a five-stage process (see Figure 2).

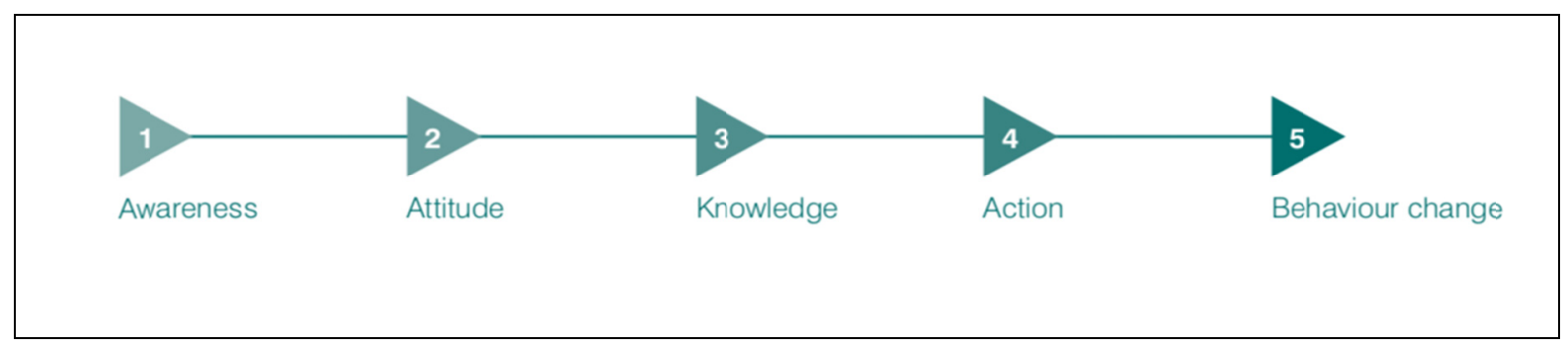

Figure 2. Model of behavioural change

Source: AITSL (2015) 
AITSL's behavioural change model involves gaining awareness, strengthening attitudes, building knowledge, taking actions and entrenching new practices. Although the guidelines are targeted towards school principals, the process can be adapted for classroom teachers. The primary stage involves teachers understanding the value of the change by gaining insights into the likely benefits that will arise from changing their approach in the classroom. The next stage involves increasing a teacher's confidence in their own ability to implement new practices, which, in turn, positively shapes their attitude towards change. The third step requires teachers to acquire the requisite knowledge to first understand, and then prepare for the necessary changes. The fourth stage is a critical juncture in successfully implementing change management among teachers, as they must demonstrate significant persistence in first performing the necessary actions to bring about change, and, once implemented, work consistently to maintain the new practices. This stage also determines the likely success of the final stage, which is where a teacher habitually implements the new actions until they become deeply entrenched.

\subsection{The Nature of Saudi Arabia Professional Development Programs}

It is apparent from the findings of this research that the Ministry of Education began the PD programs at the third step in the model, focusing on teacher learning around the acquisition of associated pedagogical knowledge. In doing so, the first and second stages of the model were neglected, i.e. attending to teacher awareness and attitude; however, these stages are essential for achieving behavioural change.

Focusing the training on the third step in the model is particularly problematic given the program's focus is not about taking action, but rather about changing behaviour. According to Gutwin and Greenberg (2001), the acquisition of awareness is an uncomplicated process, and the role and importance of awareness are generally taken for granted. Therefore, if teachers were made more aware of the role, purpose and benefits of the PDs, they may be more willing to adapt. Attitude plays an important part in teachers' willingness to change because it guides how "a person rates the target on bipolar evaluative dimensions such as how good/bad or favourable/unfavourable it is" (Petty, 2012). Despite the best intentions, by neglecting the first two stages that address awareness, the government's PD sessions have overlooked the important role that awareness and attitude play in teacher readiness for, and effective implementation of, ongoing classroom change. The lack of consideration of these factors have created a significant gap in teacher learning, resulting in a learning deficit for the teachers undertaking the programs, as reported by the participants in this study. As explained in the following section, this gap raises concerns about the planning and implementation of the program.

The study's findings point to a misalignment between the government's stated objectives of the mandatory programs and the participants' perceptions after attending the PD programs. While the seven main government objectives are both technical and educational in nature, in practice, only two of these objectives are addressed by the existing PD programs. The existing objectives laid out by the Saudi Arabian Government fail to consider some of the change management steps outlined in Figure 3.

\subsection{Tensions between Intended Objectives and Enacted Focus}

It was observed in the PD programs that there was a tendency for presenters to overlook the importance of clearly stating, and then adhering to, the government's objectives for PD programs. These actions are important, as such decisions not only impact on the program's alignment with government intentions but also impact on teacher learning.

It was understood that if the government's objectives for PDs were presented at the beginning of each PD, the participants could feel a greater sense of motivation to apply the PD's ideas to the classroom and presenters may be inclined to give closer attention to presenting content that aligns with these objectives.

During observation of these PD programs, it was noted that one presenter explained the learning objectives from the outset. His presentation expanded on one of his stated objectives by providing general information on the new science curriculum and new teaching methods (Figure 3). Technical Objective 1), which also aligns with the government's third technical objective. However, he failed to seek feedback from the participating teachers to ascertain if they understood the information. This would have enabled him to determine if his intentions had been realised. 


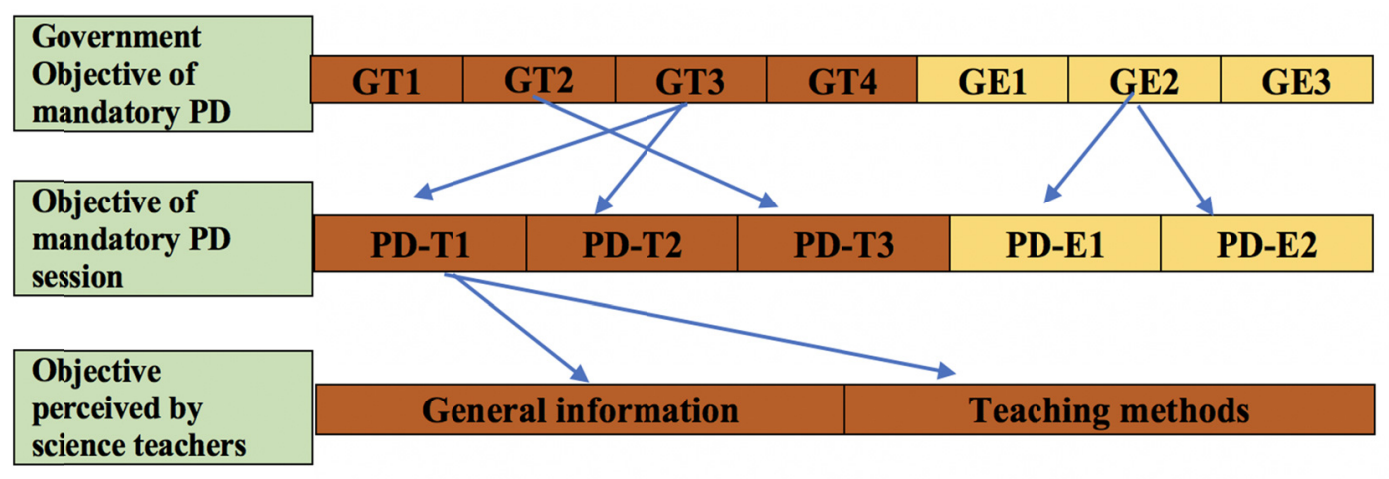

\section{$T=$ Technical Objective $\quad E=$ Educational Objective}

Figure 3. Alignment of government, PD program and science teachers' perceived objectives

These findings point to a tendency for presenters to overlook the importance of clearly stating, and then adhering to, the purposes of the PD program. Instead, their focus appeared to be fixed on technical teaching skills rather than engaging with the broader educational and technical objectives identified by the government. This practice represents a major obstacle for the realisation of the government's learning objectives in mandated PD programs. It suggests that presenters need to expand their scope of intentions to encompass broader educational and technical objectives and acknowledge that such intentions with teacher participants is an important element of teacher professional learning.

\subsection{Challenges/Implications}

These observations indicate that a filtering process is going on at both the planning and implementation levels of the PD programs. At the planning stage of the program, the government had seven PD objectives (see Figure 3); however, this became just five when the presenters gave their presentations at the PD program. Additionally, at the conclusion of the PD program, the participating teachers had only been exposed to two of the PD objectives. This situation could be a result of filtering, as it was a common situation in all three of the PD programs the researcher observed. Such changes are often referred to as a 'filtering process', where ideas are interpreted and enacted in ways that do not reflect the fidelity of the original intentions. According to Ballet and Kelchtermans (2009, p. 1155):

The actual impact of calls for change, however, is not identical for all teachers, nor is it unequivocally negative. Due to the filter processes at work, not all calls are interpreted in the same way, nor do teachers always respond identically.

In the case of the Saudi PD programs, there appears to be a real need to adjust the PD program design and examine implementation approaches to ensure that all of the government PD objectives are addressed, rather than just a limited set, as recounted by teachers based on their experiences as participants within the PD programs (see Figure 3).

Research question: What is the perceived purpose of mandatory PD programs from science teachers' perspectives?

The results of this study showed the limited scope the PD programs offered to science teachers in the Department of Education in Sarat Ubaidah. This study discusses the purpose of PD programs for science teachers and highlights that from the science teachers' perspective, 'purpose' is the main reason the PD is undertaken. Teachers perceive two main purposes for PD programs: firstly, PD provides information about the new science curriculum to the science teachers who attend these PD programs, and secondly, PD is an opportunity to obtain information about new teaching methods that may be used with the new curriculum. Teachers also mentioned other thinking about the purpose of PD that included helping teachers to deal with students and addressing classroom management issues. As previously discussed, the misalignment that exists between how teachers perceive the purpose of the mandatory PD programs and the government's objectives may be attributed to the lack of focus within the PD programs on time to explore teachers' existing ideas and their attitudes about change. 
The literature review suggests several purposes for professional development, as does the Education Policy in Saudi Arabia. For example, Leithwood (1992) mentions that PD programs can be based around skill development, competence, instructional flexibility, instructional expertise, professional growth of colleagues, leadership and decision-making, some of which are represented in the broader technical and educational objectives of the government. The inclusion of these attributes in PD programs is considered highly beneficial to the success of a PD program. According to the participants in the PD programs in Saudi Arabia, however, the programs do not cover all of these attributes and instead focus primarily on technical objectives.

While the Ministry of Education has attempted to change teacher practices in Saudi Arabia, According to Alshehry (2018, p.70), "recently, much effort has been focused on improving teaching practices in Saudi Arabia". Alshehry (2018) suggests there are some shortcomings in achieving this goal, particularly in relation to the planning of PD programs. Alshehry (2018) recognises that the Saudi Arabian Government faces challenges in planning PD programs that encapsulate all technical and educational objectives and "improve teachers' experience, beliefs and positive expectations about the importance of professional development in the teaching environment" (p. 74). One recommendation that could possibly reduce this problem could be to place greater attention on each of the five stages of the AITSL model of behavioural change while planning PD sessions (Figure 2). This means that the planning and characteristics of PD programs in Saudi Arabia require careful consideration of what is necessary in order to improve teaching practices and ultimately change teacher behaviour. For example, the Ministry of Education should have a guiding framework for all professional development activities that leads to designing meaningful learning programs for all teachers (Almazroa, \& Al-Shamrani, 2015).

Overall, the government's objectives favour the educational and technical models in implementing the new curriculum, whilst the PD programs focus primarily on technical approaches. Given the focus of the PD programs, the participants' perceptions of PD objectives match the government's PD objectives in only two of the seven PD objectives listed (information and teaching method) (see Table 1).

The disconnect between the government successfully achieving its objectives and the teachers participating in the existing PD programs may arise from the lack of consideration paid to the change management principles articulated in Figure 2. Greater investment in focusing on ways to improve participants' attitudes towards change could pay dividends in satisfying the stated objectives. The presenter needs to seek more feedback from the participants in his presentation to ensure that the purposes have been made clear and are more comprehensively understood by the participants.

The presenter also needs to place more emphasis on the PD program objectives. The results of the study suggest a lack of clear communication on the part of PD presenters in presenting program objectives, including the overall educational and technical objectives as determined by the Ministry of Education. Improving how the PD programs are presented by specifying more clearly the purpose of the PD program would work to increase the participants' learning. It was evident in some of the observed programs that the presenter focused heavily on transitioning traditional teaching methods into more active teaching methods. As a result of this approach, there was more focus on the technical teaching skills than the broader educational and technical objectives. Additionally, because the purpose of the program was not communicated clearly enough by the presenter and the focus appeared to be mainly on the technical objectives, the participants experienced some difficulty understanding the purpose of the program. For this reason, there were participants who did not specify any known purpose of the PD programs they had attended, largely because they were not informed of the purpose either prior to or during the PD programs. Thus, PD programsmust include initial descriptions of individual PD objectives in order to provide a clear understanding of the purpose of the PD. Failure to do so will result in the participants' continued lack of understanding of the purpose of the PD.

To address this issue, it would be necessary for the Ministry of Education to appoint consultants with expertise in change management to design professional development programs that incorporate strategies that focus on attitudinal change (AITSL, 2015).

Ideally, it would also be beneficial to engage specialists or otherwise train presenters to deliver this aspect of the workshop. The Ministry of Education needs to continue to transition towards an active learning model by focusing more extensively on a program that is both educational and technical. The department must continue to work towards ensuring the presenters are comprehensively communicating the program's purposes to their participants so that the material presented in the programs can be meaningfully applied in the classroom. Thus, PD programs must include initial descriptions of individual PD program objectives in order to provide a clear understanding of the purpose. Failure to do so will result in the participants' continued lack of understanding of 
the purpose of the program. Finally, the Ministry of Education must consider the importance of the change management steps outlined in Figure 2 (AITSL, 2015) when designing and implementing PD programs

\section{Conclusion for Discussion}

There is a need to include these three elements in the PD program in Saudi Arabia, specifically the PD's message needs to be made clearer to Saudi science teachers in that PD not only provides teachers with the opportunity to upskill but also allows teachers to recognise their intrinsic value to the teaching profession and see the value of working collaboratively within the school community (Mackay, 2017). This school community includes teachers, principals, students and parents of students, who form an important group of stakeholders in the fulfilment of the PD program's purpose. For example, parents can have an impact on teacher roles because of their expectations, as they may not understand or know enough about the new teaching methods and rely too much on the old ones. Also, principals and school managers may have the same ideas regarding teaching methods, and therefore not support the changes. Indeed, as Zion (2009) argues, "Change across a system as complex and dynamic as the educational system requires a systemic approach and requires the participation or buy-in of all participants and stakeholders" (p. 131).

Furthermore, so that the PD's purpose may be successfully implemented, these stakeholders should be included as part of the PD's target participants in order to get them on board with the changes involved in the field of education reform. To ensure that there is a direct translation between PD program learning and teacher practices in the classroom, the purposes of the PD should be clearly outlined for its participants.

\section{References}

Al-Qahtani, Awadh A. Y. \& Higgins, S. E. (2013). Effects of traditional, blended and e-learning on students' achievement in higher education. Journal of Computer Assisted Learning, 29(3), 220-234. Retrieved from https://doi.org/10.1111/j.1365-2729.2012.00490.x

Alabdulkareem, S. A. (2017). Saudi science teachers' perceptions of implementing inquiry in science class. Journal of Education and Training Studies, 5(12), 67-78. Retrieved from https://doi.org/10.11114/jets.v5i12.2741

Almazroa, H. \& Al-Shamrani, S. (2015). Saudi science teacher professional development: Trends, practices and future directions. In N. Mansour \& S. Al-Shamrani (Eds.), Science education in the Arab Gulf States: Visions, sociocultural contexts and challenges (pp. 3-21). Rotterdam: Springer. Retrieved from https://doi.org/10.1007/978-94-6300-049-9_1

Almazroa, H. \& Al-Shamrani, S. (2015). Saudi science teacher professional development: Trends, practices and future directions. In N. Mansour \& S. Al-Shamrani (Eds.), Science education in the Arab Gulf States: Visions, sociocultural contexts and challenges (pp. 3-21). Rotterdam: Springer. Retrieved from https://doi.org/10.1007/978-94-6300-049-9_1

Alshehry, A. (2018). Case study of science teachers' professional development in Saudi Arabia: Challenges and improvements. International Education Studies, 11(3), 70-76. Retrieved from https://doi.org/10.5539/ies.v11n3p70.

Australian Institute for Teaching and School Leadership. (2015). Australian professional standard for principals and the leadership profiles. Retrieved from https://www.aitsl.edu.au/docs/default-source/default-document-library/australian-professional-standard-forprincipals-and-the-leadership-profiles652c8891b1e86477b58fff00006709da.pdf?sfvrsn=11c4ec3c_0

Ballet, K. \& Kelchtermans, G. (2009). Struggling with workload: Primary teachers' experience of intensification. Teaching and Teacher Education, 25(8), 1150-1157. Retrieved from https://doi.org/10.1016/j.tate.2009.02.012

BenDehash, K, A. (2005). Explore the future of public education in Saudi Arabia. Paper presented at The First Arab Conference, The Future of General and Technical Education in the Arab World, Egypt.

Dastgeer, G., Tanveer, A. M., Atta, N. \& Ahmad, N. (2017). Teachers' attitude towards professional training for teaching of English writing through problem-based learning. Pakistan Journal of Social Sciences, 37(1).

Fishman, B. J., Marx, R. W., Best, S. \& Tal, R. T. (2003). Linking teacher and student learning to improve professional development in systemic reform. Teaching and Teacher Education, 19(6), 643-658. Retrieved from https://doi.org/10.1016/S0742-051X(03)00059-3 
General Directorate of Training and Scholarship. (2002). A guide to educational training and scholarship. Jeddah: Almadina Printing and Publishing.

Gutwin, C. \& Greenberg, S. (2001). The importance of awareness for team cognition in distributed collaboration. In E. Salas, S. M. Fiore \& J. A. Cannon-Bowers (Eds.), Team cognition: Process and performance at the inter- and intra-individual level. APA Press.

Hamdan, A. (2015). Challenges and constraints encountered by Saudi pre-service science teachers: A critical perspective. Learning and Teaching in Higher Education: Gulf Perspectives, 12(1).

Leithwood, K. A. (1992). The principal's role in teacher development. In M. Fullan \& A. Hargreaves (1992). Teacher development and educational change (pp. 86-103). Hoboken: Taylor and Francis.

Mackay, M. (2017). Professional development seen as employment capital. Professional Development in Education, 43(1), 140-155. doi: 10.1080/19415257.2015.1010015

Mansour, N., Heba, E. D., Alshamrani, S. \& Aldahmash, A. (2014). Rethinking the theory and practice of continuing professional development: Science teachers' perspectives. Research in Science Education, 44(6), 949-973. Retrieved from https://doi.org/10.1007/s11165-014-9409-y

McGinnis, J. R., Hestness, E., Riedinger, K., Katz, P., Marbach-Ad, G. \& Dai, A. (2012). Informal science education in formal science teacher preparation. In B. Fraser, K. Tobin \& McRobbie, C. J. (Eds.), Second international handbook of science education (Vol. 24, pp. 1097-1108). Dordrecht: Springer. Retrieved from https://doi.org/10.1007/978-1-4020-9041-7_72

Monk, D. H. (2007). Recruiting and retaining high-quality teachers in rural areas. The Future of Children, 17(1), 155-174. Retrieved from https://doi.org/10.1353/foc.2007.0009

Panizzon, D. (2011). Teaching secondary science in rural and remote schools: Exploring the critical role of a professional learning community. In D. Corrigan, J. Dillon \& R. Gunstone (Eds.), The professional knowledge base of science teaching (pp. 173-187). Netherlands: Springer. Retrieved from https://doi.org/10.1007/978-90-481-3927-9_10

Petty, R. E. (2012) Attitude change. In V. S. Ramachandran (2012). Encyclopedia of human behavior. Academic Press. Retrieved from https://doi.org/10.1016/B978-0-12-375000-6.00040-9

Rennie, L. J. (2011). Blurring the boundary between the classroom and the community: Challenges for teachers' professional knowledge. In D. Corrigan, J. Dillon \& R. Gunstone (Eds.), The professional knowledge base of science teaching (pp. 13-29). Netherlands: Springer. Retrieved from https://doi.org/10.1007/978-90-481-3927-9_2

Richardson, V. (1996). The role of attitudes and beliefs in learning to teach. In J. P. Sikula, T. J. Buttery, E. Guyton \& Association of Teacher Editors (Eds.), Handbook of research on teacher education ( ${ }^{\text {nd }}$ ed., pp. 102-119). Macmillan.

Sywelem, M. M. G. \& Witte, J. E. (2013). Continuing professional development: Perceptions of elementary school teachers in Saudi Arabia. Journal of Modern Education Review, 3, 881-898.

Zion, S. D. (2009). Systems, stakeholders, and students: Including students in school reform. Improving Schools, 12(2), 131-143. Retrieved from https://doi.org/10.1177/1365480209105577

\section{Copyrights}

Copyright for this article is retained by the author(s), with first publication rights granted to the journal.

This is an open-access article distributed under the terms and conditions of the Creative Commons Attribution license (http://creativecommons.org/licenses/by/3.0/). 